\title{
PENERAPAN MODEL PEMBELAJARAN TGT DENGAN ALAT PERAGA ULTAPHYGO UNTUK MENINGKATKAN HASIL BELAJAR MATEMATIKA SISWA
}

\author{
Hari Aningrawati Bahri' ${ }^{*}$, Herlina Rifai \\ 1Prodi Pendidikan Matematika, Universitas Al Asyariah Mandar \\ 2SMK Mega Link majene \\ *Email: aningrawatibahri@gmail.com
}

\begin{abstract}
This research is a classroom action research with the aim of knowing the improvement of student mathematics learning outcomes throught the application of the TGT learning model with Ultaphygo teaching aids. This research includes planning, implementing, observing, and reflecting. motivated by the low learning outcomes of students at SMK Mega Link Majene in mathematics. The research subjects were students of class X SMK Mega Link Majene. Data collection techniques used student activity observation sheets, learning implementation observation sheets, and student learning outcomes tests at the end of each cycle. Each data collected at the end of the cycle was analyzed quantitatively by using descriptive statistics for student learning outcomes, while student activity and learning implementation used qualitative analysis. The results showed an increase in student learning outcomes from pre cycle to first cycle. This can be seen in the average student learning outcomes in the pre-cycle test results of 78.34, then an increase in the first cycle with an average student learning outcomes of 87.66 with a completeness percentage of $89.05 \%$ of 37 students. Likewise, student activity also experienced an increase from pre-cycle an average of $78 \%$ to an average of 93\% in the first cycle with the very good category. Based on the description, it can be concluded that there is an increase in the learning achievement of students' mathematics learning activities through the application of the TGT learning model using Ultaphygo teaching aids.
\end{abstract}

Keywords: classroom action research, teams group tournament, ultaphygo, learning outcomes

\section{PENDAHULUAN}

Pembelajaran matematika sangat penting untuk menunjang pembelajaran pada mata pelajaran lain. Hal ini sesuai dengan Peraturan Menteri Pendidikan Nasional Nomor 22 Tahun 2006 tentang Standar Isi, bahwa mata pelajaran matematika perlu diberikan kepada semua siswa mulai dari sekolah dasar untuk 
membekali siswa dengan kemampuan berpikir logis, analitis, sistematis, kritis, dan kreatif, serta kemampuan bekerjasama. Dalam upaya meningkatkan kualitas Pendidikan menjadi lebih baik, dibutuhkan tenaga-tenaga pendidik yang bukan hanya cerdas dalam mengajarkan ,materi pelajaran, namun juga harus tanggap dalam melihat kemampuan dan kebutuhan setiap siswa. Berbagai kendala yang dihadapi guru dalam pembelajaran matematika karena masih banyak siswa yang berpandangan negative pada mata pelajaran ini. Siswa masih menganggap bahwa matematika adalah pelajaran yang sulit dan menjadi beban belajar bagi mereka. Berdasarkan hasil pengamatan juga terlihat pada keaktifan siswa dalam pembelajaran sangat kurang, hanya sebagian kecil siswa yang terlihat antusias dalam bertanya dan menjawab pertanyaan dari guru, sehingga pembelajaran terlihat monoton dan interaksi antara guru dan siswa begitupun antara siswa sangat kurang.

Berkaca dari hal tersebut bahwa pemilihan model dan media pembelajaran sangat penting dalam proses pembelajaran, maka dibutuhkan upaya guru untuk kreatif dalam memilih dan menggunakan model dan alat peraga untuk menunjang terlaksananya pembelajaran. Berdasarkan hasil observasi awal di SMK Mega Link Majene melalui guru mata pelajaran matematika bahwa nilai yang dicapai siswa masih dibawa standar atau tidak mencapai KKM. Dari 32 siswa hanya 56\% yang mencapai nilai ketuntasan KKM. Sedangkan nilai ketuntasan secara klasikal adalah 85\% yang berarti bahwa hasil tes kemampuan pemecahan masalah siswa masih sangat rendah, untuk mengatasi permasalahan ini diperlukan alat peraga matematika yang menarik motivasi siswa untuk aktif dalam proses pembelajaran. Alat peraga ULTAPHYGO (Ular Tangga Pythagoras) adalah alat yang dibuat berupa permainan ular tangga yang setiap kotaknya berisi pertanyaan mengenai teorema Pythagoras.

Proses pembelajaran akan berjalan lebih baik dan menumbuhkan kreativitas dan motivasi siswa untuk menyelesaikan masalah yang diberikan jika guru menggunakan model dan media yang sesuai dengan materi pembelajaran. Hal ini juga sejalan dengan penelitian yang dilakukan oleh Ahmad (2018) penerapan alat peraga kotak dadu matematika (kodama) dapat memotivasi siswa untuk menyelesaikan soal matematika. Sebagaimana tujuan pembelajaran matematika dalam Departemen Pendidikan Nasional (Susanto, 2013) bahwa "tujuan pembelajaran matematika adalah (1) memahami konsep matematika; (2) menggunakan penalaran pada pola dan sifat; (3) memecahkan masalah; (4) mengkomunikasikan gagasan; dan (5) memiliki sikap saling menghargai kegunaan matematika dalam kehidupan."

Penelitian ini bertujuan untuk mengetahui peningkatan hasil belajar siswa melaui penerapan model pembelajaran kooperatif tipe TGT dengan alat peraga ULTAPHYGO. TGT adalah salah satu tipe pembelajaran kooperatif yang 
mendapatkan siswa dalam kelompok-kelompok belajar yang beranggotakan 5 sampai 6 orang siswa yang memiliki kemampuan, jenis kelamin dan suku kata atau ras yang berbeda. Guru menyajikan materi, dan siswa bekerja dalam kelompok mereka masing-masing. Dalam kerja kelompok guru memberikan LKS kepada setiap kelompok. Tugas yang diberikan dikerjakan bersama-sama dengan anggota kelompoknya. Apabila ada dari anggota kelompok yang tidak mengerti dengan tugas yang diberikan, maka anggota kelompok yang lain bertanggung jawab untuk memberikan jawaban atau menjelaskannya, sebelum mengajukan pertanyaan tersebut kepada guru. Berikut adalah tabel 1 siklus pembelajaran kooperatif tipe TGT.

Tabel 1. Siklus pembelajaran kooperatif tipe TGT

\begin{tabular}{|c|c|}
\hline Fase & Tingkah Laku Guru \\
\hline $\begin{array}{l}\text { Fase } 1 \\
\text { Menyampaikan tujuan } \\
\text { dan memotivasi siswa. }\end{array}$ & $\begin{array}{l}\text { Guru menyampaikan semua tujuan pelajaran } \\
\text { yang ingin dicapai pada pelajaran tersebut dan } \\
\text { memotivasi siswa belajar. }\end{array}$ \\
\hline $\begin{array}{l}\text { Fase } 2 \\
\text { Menyampaikan informasi. }\end{array}$ & $\begin{array}{l}\text { Guru menyampaikan informasi kepada siswa } \\
\text { dengan jalan demonstrasi atau lewat bahan } \\
\text { bacaan. }\end{array}$ \\
\hline $\begin{array}{l}\text { Fase } 3 \\
\text { Mengorganisasikan siswa } \\
\text { ke dalam kelompok- } \\
\text { kelompok belajar. }\end{array}$ & $\begin{array}{l}\text { Guru membagi siswa dalam beberapa yang } \\
\text { beranggotakan 5-6 orang berdasarkan kinerja } \\
\text { akademik (sesuai model pembelajaran } \\
\text { kooperatif tipe TGT). }\end{array}$ \\
\hline $\begin{array}{l}\text { Fase } 4 \\
\text { Membimbing kelompok } \\
\text { bekerja dan belajar. }\end{array}$ & $\begin{array}{l}\text { Guru membimbing kelompok belajar pada saat } \\
\text { mereka mengerjakan tugas yang akan } \\
\text { diturnamenkan. }\end{array}$ \\
\hline $\begin{array}{l}\text { Fase } 5 \\
\text { Evaluasi. }\end{array}$ & $\begin{array}{l}\text { Guru mengevaluasi hasil tes kemampuan } \\
\text { pemecahan masalah tentang materi yang telah } \\
\text { dipelajari atau masing-masing kelompok } \\
\text { mempresentasikan hasil kerjanya. }\end{array}$ \\
\hline
\end{tabular}




\begin{tabular}{|l|l|}
\hline \multicolumn{1}{|c|}{ Fase } & \multicolumn{1}{|c|}{ Tingkah Laku Guru } \\
\hline Fase 6 & Guru mencari cara untuk menghargai baik \\
Memberikan penghargaan. & upaya maupun hasil tes kemampuan \\
& pemecahan masalah individu dan kelompok. \\
\hline
\end{tabular}

Alat peraga dalam pembelajaran adalah segala benda yang dirancang sedemikian rupa dan sengaja dipersiapkan untuk digunakan sebagai media dalam pembelajaran dengan maksud agar materi pelajaran yang disampaikan guru dapat dengan mudah dimengerti oleh siswa. Menurut Pranata (2016) alat peraga adalah alat yang menerangkan atau mewujudkan konsep matematika, sedangkan Sulistyorini (2017) benda konkrit yang dibuat, dihimpun, atau disusun secara sengaja digunakan untuk membantu menanamkan atau mengembangkan suatu konsep matematika.

Alat peraga ULTAPHYGO (Ular Tangga Phytagoras) adalah alat yang dibuat berupa permainan ular tangga yang setiap kotaknya berisi pertanyaan mengenai teorema Phytagoras. Cara penggunaannya tidak jauh berbeda dengan permainan ular tangga pada umumnya. Perbedaan dsini adalah kotak yang digunakan bukan seperti kotak biasanya yang terdapat pada kotak ular tangga, tapi disini kotak tersebut ditambahkan tulisan pertanyaan yang akan dijawab oleh siswa mengenai teorema Phytagoras. Siswa akan menjawab pertanyaanpertanyaan pada kotak ular tangga setelah melempar dadu sesuai dengan angka dadu yang muncul. Alat peraga ULTAPHYGO ini selain bermain seperti ular tangga pada umumnya siswa juga mendapatkan pengetahuan mengenai teorma Phytagoras melalui permainan terebut. Media ULTAPHYGO dapat dilihat dari Gambar 1 berikut.

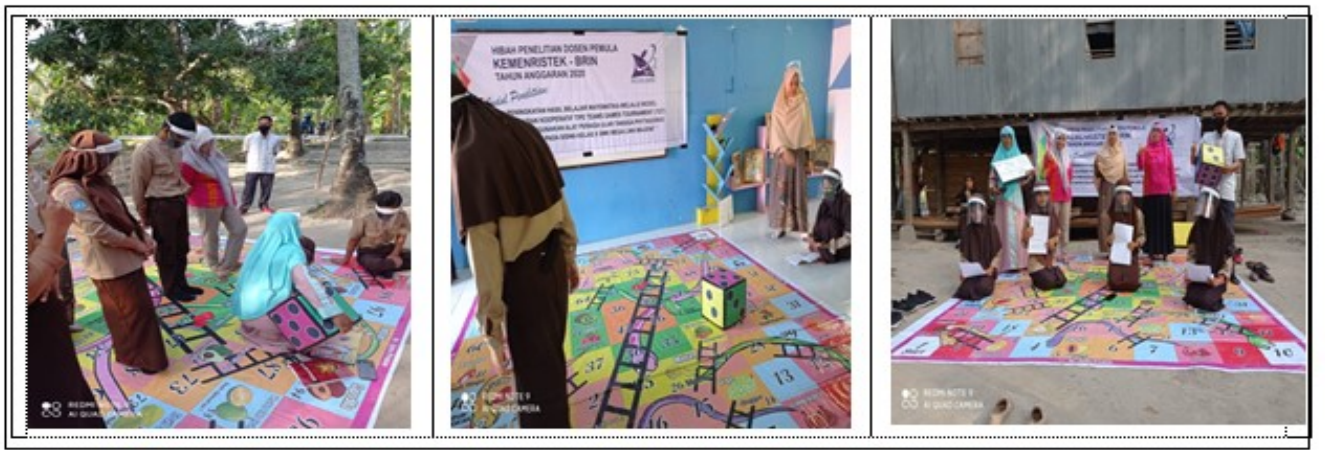

Gambar 1. Alat Peraga ULTAPHYGO 


\section{METODE PENELITIAN}

Penelitian ini merupakan penelitian tindakan kelas dalam upaya meningkatkan hasil belajar siswa. Penelitian menurut Arikunto (Susyanto, 2016) penelitian tindakan kelas merupakan suatu pencermatan terhadap kegiatan yang sengaja dimunculkan, dan terjadi dalam sebuah kelas. Dalam penelitian ini, peneliti berkolaborasi dengan guru mulai dari merencanakan pembelajaran dan melaksanakan tindakan guna memperbaiki proses pembelajaran. Penelitian tindakan kelas ini dilaksanakan dengan dua siklus dan setiap siklus terdiri dari empat tahapan, yaitu: (1) membuat perencanaan; (2) pelaksanaan; (3) observasi; dan (4) refleksi. Subyek penelitian ini adalah siswa kelas X SMK Mega Link Majene, Instrumen yang digunakan ialah lembar observasi aktivitas guru dan siswa, dan hasil tes evaluasi yang dilakukan setiap akhir siklus.

Data yang terkumpul dianalisis dengan menggunakan teknik analisis kuantitatif dan kualitatif. Data tentang hasil pengamatan aktivitas siswa dan responss siswa dianalisis secara kualitatif sedangkan data tentang hasil belajar di analisis secara kuantitatif dengan mengunakan statistik deskriptif yaitu skor ratarata dan presentase, standar devisi, frekuensi, dan persentase nilai terendah dan nilai tertinggi yang dicapai siswa setiap siklus.

Indikator keberhasilan siswa dalam penelitian tindakan kelas ini adalah:

Apabila hasil tes siswa yang menunjukkan peningkatan ketuntasan belajar atau skor rata-rata hasil belajar metematika. Menurut ketentuan KKM di SMK Mega Link Majene bahwa siswa dikatakan tuntas belajar jika memperoleh skor minimal 73\% dari skor ideal, dan tuntas secara klasikal apabila minimal 85\% dari jumlah siswa yang telah tuntas belajar.

\section{HASIL DAN PEMBAHASAN}

Penelitian ini diawali dengan kegiatan observasi untuk mengidentifikasi permasalahan yang terjadi dalam proses pembelajaran dan sebagai upaya mencari solusi. Tahap selanjutnya yang dilakukan peneliti adalah tahap pelaksanaan yaitu siklus untuk mencapai indikator keberhasilan. Adapun penerapan model pembelajarn TGT dengan alat peraga Ultaphygo dalam penelitian tindakan kelas dilakukan terdiri dari empat tahap yaitu (1) membuat perencanaan; (2) pelaksanaan; (3) observasi; dan (4) refleksi.

1) Perencanaan (Planning).

Kegiatan awal yang dilakukan pada tahap perencanaan ini menganalisis masalah yang terjadi dalam proses pembelajaran serta mencari alternatif pemecahan masalahnya. Tahap awal adalah 1) menetapkan indicator ketercapaian 
pembelajaran, 2) menyusun RPP, 3) menyusun instrument tes hasil belajar, 4) menyusun lembar observasi aktivitas siswa dan keterlaksanaan pembelajaran.

2) Pelaksanaan

Pada tahap ini guru menerapkan model pembelajaran TGT dengan bantuan alat peraga Ultaphygo dengan materi pembelajaran phytagoras. Pelaksanaan pembelajaran dilakukan di luar kelas dengan pembelajaran secara luring. Dengan membagi siswa ke dalam kelompok-kelompok yang heterogen.

3) Observasi dan Evaluasi

Observasi Pelaksanaan proses pembelajaran dengan menggunakan lembar observasi aktivitas siswa dan keterlaksanaan pembelajaran. Hasil penilaian pengisian instrumen observasi tindakan guru dan siswa disajikan pada table berikut.

Table 2. Hasil observasi keterlaksanaan pembelajaran dan aktivitas siswa Sumber: Hasil Olah Data 2020

\begin{tabular}{|l|l|l|l|l|}
\hline \multirow{2}{*}{ Hasil observasi } & \multicolumn{2}{|c|}{ Rata-rata persentase } & \multicolumn{2}{c|}{ Kesimpulan } \\
\cline { 2 - 5 } & Prasiklus & Siklus I & Rata-rata & kategori \\
\hline $\begin{array}{l}\text { Observasi keterlaksanaan } \\
\text { pembelajaran }\end{array}$ & 73,21 & 85 & 83,19 & Baik \\
\hline Observasi aktivitas siswa & 78 & 93 & 91 & Sangat baik \\
\hline
\end{tabular}

Pada table di atas terlihat aktivitas siswa pada saat prasiklus sebesar $78 \%$ mengalami peningkatan pada siklus I menjadi 93\% dari 37 siswa berada [ada kategori dangat baik. Hal ini menandakan bahwa sebagian besar siswa terlibat aktif dalam proses pembelajaran. Demikian halnya hasil observasi keterlaksanaan yang berada pada kategori baik yang menandakan bahwa model pembelajaran TGT dengan alat peraga ultaphygo dapat terlaksana dengan baik berdasarkan langkah-langkah pembelajaran yang telah direncanakan.

\section{Hasil Belajar Siswa}

\section{Analisis Deskriptif Kuantitatif}

Data hasil tes kemampuan pemecahan masalah siswa diperoleh setelah melakukan pretest dan posttest setelah menerapkan model kooperatif tipe TGT dengan alat peraga ULTAPHYGO dengan materi pembelajaran yaitu phytagoras. 
Tabel 3. Analisis Deskriptif

Sumber: Hasil Olah Data 2020

\begin{tabular}{|l|c|l|l|l|l|}
\hline & N & Mean & Std. Deviation & Skor terendah & Skor tertinggi \\
\hline Siklus I & 38 & 87.7105 & 4.24842 & 86,26 & 89,05 \\
\hline Presiklus & 38 & 78.3947 & 2.88087 & 77,39 & 79,29 \\
\hline Valid N (listwise) & 38 & & & & \\
\hline
\end{tabular}

Dari data analisis deskriptif di atas, terlihat bahwa nilai terendah siswa pada siklus I bahkan lebih tinggi daripada nilai tertinggi pada saat presiklus yaitu sebesar 86,26 dengan skor tertinggi sebesar 89,05. Sementara untuk rata-rata hasil belajar siswa pada presiklus hanya sebesar 78,39\%. Setelah diterapkan model pembelajaran kooperatif tipe Team Games Tournament (TGT) dengan alat peraga Ultaphygo, hasil belajar siswa mengalami peningkatan dengan rata-rata $87,71 \%$.

Table 4. Deskripsi ketuntatasan belajar siswa kelas X SMK Mega Link Majene Sumber: Hasil Olah Data 2020

\begin{tabular}{|l|l|l|l|}
\hline \multicolumn{1}{|c|}{ Skor } & \multicolumn{1}{c|}{ Kategori } & \multicolumn{1}{c|}{ Frekuensi } & \multicolumn{1}{c|}{ Persentase \% } \\
\hline $0-75$ & Tidak tuntas & 4 & 9,68 \\
\hline $76-100$ & Tuntas & 34 & 90,32 \\
\hline Jumlah & $\mathbf{3 8}$ & $\mathbf{1 0 0}$ \\
\hline
\end{tabular}

Dari hasil belajar di siklus I terlihat bahwa secara individu, jumlah siswa yang memperoleh skor minimal 76 dari skor ideal 100 adalah 38 siswa dari 38 orang siswa atau $90,32 \%$ yang mengalami ketuntasan individu, sedangkan 4 orang siswa atau 9,68\% belum mencapai ketuntasan secara individu. Hal ini menandakan bahwa bahwa secara individu hasil tes belajar siswa telah memenuhi standar minimum sebesar $75 \%$ dan secara klasikal telah memenuhi standar yakni sebesar $85 \%$ dari jumlah siswa yang tuntas belajar secara individu.

4) Refleksi

Pada awal siklus, terlihat pelaksanaan moidel pembelajaran TGT dengan alat peraga Ultaphygo berjalan dengan sangat baik dan sebagian besar siswa terlihat sangat antusias dan juga aktif dalam pembelajaran. Dengan pembelajaran yang menyenangkan namun tetap focus pada pembelajaran, siswa lebih mudah untuk memahami pembelajaran dan juga mengutarakan pendapat dan 
pertanyaan-pertanyaan terkait materi pelajaran semakin meningkat jika dibandingkan pada prasiklus.

\section{SIMPULAN}

Berdasarkan hasil penelitian dan pembahasan, dapat disimpulkan bahwa hasil belajar dan aktivitas siswa dalam penerapan model pembelajaran TGT dengan alat peraga Ultaphygo mengalami peningkatan. Dari hasil belajar di prasiklus menunjukkan bahwa secara individu, jumlah siswa yang memperoleh skor minimal 76 dari skor ideal 100 adalah 38 siswa dari 38 orang siswa atau $90,32 \%$ yang mengalami ketuntasan individu, sedangkan 4 orang siswa atau 9,68\% belum mencapai ketuntasan secara individu. Hal ini menandakan bahwa bahwa secara individu hasil tes belajar siswa telah memenuhi standar minimum sebesar 75\% dan secara klasikal telah memenuhi standar yakni sebesar 85\% dari jumlah siswa yang tuntas belajar secara individu. Hasil belajar matematika siswa kelas X SMK Mega Link Majene melalui pembelajaran TGT dengan alat peraga Ultaphygo mengalami peningkatan.

\section{SARAN}

Peneliti merekomendasikan agar tenaga pengajar dalam pembelajaran lebih menggunakan media-media atau alat peraga yang menyenangkan sehingga siswa dapat lebih antusias dalam pembelajaran, dan sebelum menerapkan model dan penggunaan alat peraga tertentu agar guru-guru dapat menelaah kemampuan siswa sehingga pemilihan model pembelajaran dan alat peraga dapat sesuai dengan kebutuhan siswa. Selalu mengevaluasi kualitas pembelajarannya dan dapat merencanakan solusi untuk perbaikan -perbaikan kedepannya.

\section{DAFTAR PUSTAKA}

Ahmad, H. (2018). Efektivitas Penggunaan Alat Peraga Kodama dalam Mengerjakan Soal Matematika. Pepatudzu: Media Pendidikan dan Sosial Kemasyarakatan, 13(2), 118-132.

Pranata, E. (2016). Implementasi Model Pembelajaran Group Investigation (GI) Berbantuan Alat Peraga Untuk Meningkatkan Kemampuan Pemahaman Konsep Matematika. JPMI (Jurnal Pendidikan Matematika Indonesia), $1(1), 34-38$.

Sulistyorini, S. (2017). Manajemen Pembelajaran Matematika Menggunakan Alat Peraga Blok Pecahan, Lingkaran dan Kartu Pecahan. Manajer Pendidikan, $11(2)$.

Susanto, A. (2013). Teori Belajar dan Pembelajaran di Sekolah Dasar; Edisi 
p-ISSN: 2087-3476

e-ISSN: $2541-5700$

Pepatuzdu: Media Pendidikan dan Sosial Kemasyarakatan

Vol 16, No. 2 November 2020

Pertama. Jakarta: Kencana.

Susyanto, AD. 2016. Upaya Meningkatkan Hasil Belajar Matematika melalui Pembelajaran Kooperatif Tipe Team Games Tournamen. Universitas PGRI Yogyakarta. repository.upy.ac.id/153/1/Jurnal 